ISSN: 1641-4713; e-ISSN: 2081-1160

DOI: https://doi.org/10.36551/2081-1160.2020.26.327-346

\title{
El Movimiento Ecuménico y los orígenes mendocinos de la Teología de la Liberación
}

\author{
Ecumenism at the genesis of Liberation Theology
}

\section{Guillermo Barón}

Facultad de Ciencias Políticas y Sociales

Universidad Nacional de Cuyo, Argentina

ORCID iD: http://orcid.org/0000-0003-3044-7236

E-mail: guillermobaron@yahoo.com

Recepción: 30.04.2020

Aprobación: 2.07.2020

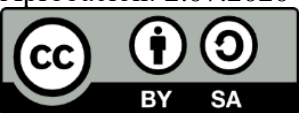

Resumen: En el siguiente artículo nos proponemos matizar y reformular la idea popularizada por Michael Löwy de una afinidad electiva entre catolicismo y anticapitalismo en la base de la Teología de la Liberación Latinoamericana. Para ello trazamos un recorrido histórico del diálogo ecuménico en el origen de esta corriente en uno de sus polos sudamericanos: la ciudad de Mendoza, en Argentina. Como conclusión proponemos revisitar las definiciones de izquierda cristiana, movimiento ecuménico y teología de la liberación.

Palabras clave: Teología de la liberación, Movimiento ecuménico, afinidad electiva, izquierda cristiana, anti-capitalismo cristiano, años 60 , Argentina.

Abstract: We propose in this paper a refinement and reformulation of the idea, popularized by
Michael Löwy in his book The War of the Gods, of an elective affinity between Catholicism and
anti-capitalism at the base of Latin American Liberation Theology. For this, we trace the story of
the ecumenical dialogue at its origins in one of its South American poles, the city of Mendoza,
Argentina. As a conclusion, we propose to revisit the definitions of Christian left, ecumenical move-
ment, and liberation theology.

Keywords: Liberation theology, Ecumenical movement, elective affinity, Christian left, Christian anti-capitalism, 1960s, Argentina. 
INTRODUCCIÓN: LA “AFINIDAD ELECTIVA” ENTRE CATOLICISMO

Y ANTICAPITALISMO EN LA BASE DE LA TEOLOGÍA DE LA LIBERACIÓN

En Guerra de dioses. Religión y política en América Latina (1999), el sociólogo franco-brasileño Michael Löwy señala la existencia de una afinidad negativa entre catolicismo y capitalismo como condición de posibilidad del nacimiento de la Teología de la liberación en América Latina. Para Löwy, se trata de una contrapartida o complemento necesario de la tesis weberiana acerca de la afinidad electiva entre ética protestante y espíritu capitalista. Un "capítulo no escrito" de la sociología weberiana que debería ser reconstruido:

Y ¿qué hay con la importancia económica de la ética católica? Max Weber nunca escribió una evaluación sistemática de las relaciones entre el catolicismo y el ethos capitalista, pero hay un evidente "subtexto", un contraargumento no escrito integrado en la estructura misma de La ética protestante: la Iglesia católica es un entorno mucho menos favorable -si no es que francamente hostil- para el desarrollo del capitalismo que las sectas calvinista o metodista. (Löwy, 1999, p. 31)

La idea de que el catolicismo representaba una especie de dique de contención contra los valores capitalistas no era novedosa en un país como la Argentina. Formaba parte de cierto sentido común del nacionalismo católico de principios y mediados del siglo XX y desde allí había logrado filtrarse hacía algunas corrientes del antiimperialismo revolucionario (Míguez Bonino, 1995). Como clave interpretativa resultaba, además, bastante simple y tentadora.

Si bien es cierto que la relación entre catolicismo y anticapitalismo se encuentra presente como tema en muchas manifestaciones particulares de la Teología de la liberación, falla para entender al catolicismo como un todo homogéneo - ¿qué hacer, por ejemplo, frente a sectas católicas híper adaptadas al espíritu de empresa y sus exigencias, como el Opus Dei? -. Tampoco nos resulta útil para explicar a los movimientos liberacionistas que se desarrollaron a partir de experiencias progresistas o liberales dentro del mismo catolicismo -y no a partir de aquellas más tradicionalistas-, y nos haría faltar a la verdad si nos llevara a argumentar que el catolicismo es un terreno necesariamente más fértil para el anticapitalismo que el mundo protestante.

Nos detendremos en esto último por un momento. Es cierto que en América Latina el liberacionismo protestante es numéricamente más restringido que el liberacionismo católico, pero tal vez esto se deba a que las comunidades protestantes son también minoritarias en relación con la población total. Además, más allá de la importancia numérica de las comunidades, se debe tomar en cuenta también la significación y el nivel teórico alcanzados por la Teología de la liberación de cuño protestante: 
[...] es bueno recordar que la primera vez que aparece sistematizado el concepto de teología de la liberación, éste no proviene del ámbito católico sino protestante. Es la tesis de doctorado del presbiteriano brasileño Rubem Alves, defendida en 1968, que tiene como título "Por una teología de la liberación". Un autor extremadamente rico (y a veces complejo) en su propuesta de una teopoética (una combinación de teología y poesía) que intenta responder a cuestiones centrales que se plantea el ser humano en el mundo contemporáneo. (Kerber, 2013, p. 1820)

Otra interesante definición, la de romanticismo, es ensayada por Löwy y Robert Sayre en Rebelión y melancolía. El romanticismo como contracorriente de la modernidad: "[...] el romanticismo representa una crítica de la modernidad, es decir de la civilización capitalista moderna, en nombre de valores y de ideales del pasado (precapitalista, premoderno)". (Löwy \& Sayre, 2008, p. 28)

Según estos dos autores, el romanticismo no sería ni un movimiento artístico ni una tradición política, sino una Weltanschauung o estructura de sentido a la manera goldmanniana, que puede manifestarse entonces tanto como sensibilidad estética o como criterio político. En ambos casos, implica siempre un rechazo - a veces reaccionario, otras revolucionario, siempre nostálgico-a las principales características de la sociedad capitalista; esto es, siguiendo a Max Weber, el espíritu de cálculo, el desencanto del mundo, la racionalidad instrumental y la dominación burocrática (Löwy \& Sayre, 2008).

Entre las múltiples expresiones artísticas, políticas, religiosas y sociales que los autores entienden como manifestación del romanticismo en tanto estructura de sentido, se encontraría también la teología de la liberación:

La teología de la liberación incluye a la vez aspectos románticos y "antimodernistas" crítica de la modernidad capitalista, nostalgia de la comunidad orgánica- y aspectos utópicos que miran al provenir: la aspiración a una sociedad igualitaria, sin clases ni opresión. Desde ese punto de vista, está próxima al tipo romántico-revolucionario. Su crítica del capitalismo en América latina articula la tradición "anticapitalista romántica" del catolicismo -condena moral y religiosa de la economía mercantil- con el análisis marxista de la explotación imperialista. Esta doble naturaleza, a la vez "progresista" y antimoderna, se vuelve a encontrar en todos los niveles de reflexión de los teólogos de la liberación. Partidarios de la democracia, desean la separación entre la Iglesia y el Estado, rechazan la idea de un "partido católico" y defienden la autonomía de los movimientos sociales. Pero comparten con la corriente católica intransigente el rechazo a la privatización de la fe y a la separación (típicamente moderna) de las esferas política y religiosa. (Löwy \& Sayre, 2008, p. 195)

En otra parte, los autores destacan la afinidad entre el pensamiento romántico y el regreso a las tradiciones místicas y religiosas, coherente con su rechazo al desencantamiento del mundo. Es más, en muchos de los antecedentes relevados por Löwy y Sayre, la religión sería el rasgo principal del espíritu romántico, dado que en la gran mayoría de los románticos -sobre todo en los del siglo XIX - hay una búsqueda apasionada por la restauración de las religiones del pasado, particularmente del catolicismo medieval. Esto llegaría a ser así incluso 
en casos de apropiación marxista de la crítica romántica -o viceversa-como los de György Lukács o Ernst Bloch.

Löwy y Sayre reconocen una gran parte de verdad en esta asociación, pero para ellos el romanticismo sería un fenómeno mucho más amplio:

[...] por una parte, porque existe un romanticismo arreligioso (Hoffmann) e incluso antirreligioso (Proudhon, Nietzsche, O. Panizza) y, por otra parte, porque no permiten distinguir las formas románticas de otras formas de religiosidad, a la manera de ciertos tipos de protestantismo que se adaptan perfectamente, como había constatado Max Weber, al "espíritu del capitalismo". (Löwy \& Sayre, 2008, p. 41)

Como conclusión, tenemos que hay una suerte de espíritu anticapitalista que puede ser vinculado al catolicismo, pero como hemos visto, no sólo al catolicismo, ya que existe una teología de la liberación protestante. Por otro lado, este anticapitalismo no se extendería a todo el catolicismo, ya que hay un catolicismo afín al capitalismo. De manera más general, existe una estructura de sentido romántica que se relaciona con lo religioso, a pesar de que también se encuentra presente en lo arreligioso e incluso en lo antirreligioso. Al tratar de abarcarlo todo, las tesis de Löwy parecen perder algo de su fuerza explicativa.

Tal vez debiéramos volver a Weber para tratar de entender por qué no escribió el capítulo sobre la ética católica y el capitalismo. Efectivamente, en un fragmento que Löwy cita, Weber escribe que:

El dinero es lo más abstracto e "impersonal" que existe en la vida humana. Cuanto más se acomoda el mundo de la economía capitalista a sus propias leyes internas tanto más dificulta toda posible relación con una ética religiosa de la fraternidad. Ello ocurre tanto cuanto más racional, y por ende más impersonal, deviene el capitalismo. Antiguamente era posible una regulación ética de las relaciones entre amo y esclavo, justamente porque eran relaciones personales. Pero no pueden regularse -o por lo menos no en igual sentido y con igual éxito- las relaciones entre los titulares de hipotecas, siempre variables, y los deudores de los Bancos emisores, igualmente variables; en esta situación no existe, efectivamente, ninguna clase de vínculo personal. (Weber, 1978, pp. 68-69) ${ }^{1}$

Para Weber no es el catolicismo en sí lo que es hostil al capitalismo, sino la ética religiosa de la fraternidad, donde quiera que esta regule las relaciones humanas. La afinidad entre la ética del puritanismo calvinista y el espíritu del capitalismo radicaría en que "como religión de virtuosos, el puritanismo abandonó el universalismo del amor" (Weber, 1978, p. 70). Esto no implica necesariamente que la ética de la fraternidad sea patrimonio exclusivo del catolicismo, ni que siempre predomine en él como único criterio ${ }^{2}$. Por otro lado, tampoco estaría

\footnotetext{
${ }^{1}$ Las cursivas de la cita son nuestras.

${ }^{2} \mathrm{Ni}$ que cuando predomine no se transforme en una coartada de dominación. Piénsese por ejemplo en la transformación del ser humano en un alma, inmaterial e inmortal, que justifica el martirio del cuerpo por el amor al alma/prójimo. Ver Hinkelammert, 1981.
} 
tan claro que se encuentre ausente de otras formas de cristianismo no católico, incluidos calvinismo y metodismo.

En nuestra opinión, Löwy sobrestima el papel jugado por los católicos en la construcción de un cristianismo de la liberación, a la vez que subestima el de otros cristianos y el de los católicos mismos como parte de un movimiento más amplio de cristianismo ecuménico. Quizá esto se deba a su excesivo celo por mantener las tesis weberianas, o a que sus estudios se centran en el caso brasilero, donde las tendencias liberacionistas lograron volverse hegemónicas dentro de la Iglesia Católica. Creemos que el nacimiento de un cristianismo liberacionista en América latina obedeció, antes que nada, a lo que entonces se percibía como un escenario revolucionario o pre-revolucionario. Dicho escenario tuvo una potencia de interpelación fortísima tanto para católicos como para protestantes. Si de condiciones de posibilidad se trata, fue el diálogo ecuménico y no la afinidad electiva lo que permitió a los fieles de las distintas denominaciones criticar y reconstruir un cristianismo nuevo, mejor adaptado a los fines de la liberación.

Para finalizar esta introducción, nos parece necesario establecer algunas breves aclaraciones sobre nuestros objetivos y metodología. Al comenzar a indagar sobre los orígenes mendocinos del cristianismo liberacionista y la teología de la liberación, Guerra de Dioses, el libro de Michael Löwy, era una lectura obligatoria. Sin embargo, poco a poco, fuimos confirmando cómo nuestro caso particular de estudio no se acomodaba del todo a los supuestos del investigador franco-brasileño. El caso mendocino se caracterizaba por un diálogo altamente fructífero entre católicos y protestantes, en donde fueron estos últimos los que, muchas veces, tomaron la iniciativa y ostentaron las posiciones más avanzadas. Es más, dado que las posiciones oficiales de la Iglesia católica argentina eran francamente hostiles al liberacionismo, podemos decir que la ayuda ecuménica y protestante fue también una de las condiciones de posibilidad de la acción y el pensamiento liberacionista de origen católico.

En este trabajo nos hemos asentado en testimonios, tanto de actores protestantes como católicos, para tratar de establecer una concatenación de hechos, relaciones y redes político-intelectuales. También nos hemos basado en estudios sobre los movimientos político-religiosos que antecedieron y fueron dando forma al ecumenismo de los años 60. Como resultado de ese recorrido, proponemos una serie de definiciones y redefiniciones en torno al movimiento ecuménico, al cristianismo liberacionista y a la izquierda cristiana. 


\section{BREVE RESEÑA HISTÓRICA DEL MOVIMIENTO ECUMÉNICO}

Si tuviéramos que establecer un hito fundacional formal del movimiento ecuménico mundial, lo más adecuado sería referirse a la creación en Ámsterdam del Consejo Mundial de Iglesias -CMI- en el año 1948 (Míguez Bonino, 1995). Sin embargo, los antecedentes del movimiento pueden rastrearse hasta la Conferencia Misionera Mundial de Edimburgo, en 1910, que supuso la creación del Consejo Misionero Internacional ${ }^{3}$ en 1921, o las conferencias de Estocolmo en 1925 y Lausana en 1927. El movimiento se originaba a partir de una inquietud fundamental: ¿cómo dar testimonio fiel de la fe si las iglesias se hallaban desunidas? De manera consustancial, aparecían también los problemas de la misión evangélica en los países no-cristianos de Asia, África y Oceanía, los cuales se encontraban en su mayor parte bajo el yugo de la dominación colonial occidental. En la Asamblea de 1948:

Todas las familias confesionales, excepto por los católicos romanos, estuvieron representadas. Un número de católicos romanos había sido invitado para asistir como observadores, pero no pudieron aceptar la invitación porque en junio el Santo Oficio había publicado un Monitum ${ }^{4}$ a efectos de que ningún católico romano recibiera permiso de asistir. (Visser 't Hooft, 1982, p. 63)

Por otro lado, en Amsterdam:

Las iglesias jóvenes estuvieron más fuertemente representadas de lo que habían estado en Oxford o Edimburgo; fueron principalmente iglesias asiáticas, las cuales enviaron 22 delegados. Muy pocas iglesias jóvenes de África y América Latina pudieron alistarse para unirse al Consejo. (Visser 't Hooft, 1982, p. 64)

Esta situación, como veremos, se iría modificando durante la década de los años 50, para alcanzar un momento álgido de involucramiento latinoamericano en el CMI en la década de los años 60.

En la Argentina, las iniciativas del protestantismo en términos políticos y sociales venían siendo muy restringidas y, en general, apuntaban a la modernización, liberalización y democratización de las sociedades criollas. Se trataba de minorías religiosas que buscaban un lugar bajo el sol en un escenario hostil, dominado particularmente por la Iglesia Católica y su creciente penetración en el Estado -principalmente en las FF.AA.-, las que a partir de 1930 serán las que detenten el poder estatal con mayor frecuencia (Míguez Bonino, 1995; Mallimaci, 2008; Zanatta, 1996).

La libertad religiosa es entonces la principal bandera de las iglesias protestantes que participaban, a nivel mundial y regional, en el movimiento

\footnotetext{
${ }^{3}$ En 1961 se fusionaría con el Consejo Mundial de Iglesias.

${ }^{4}$ Advertencia canónica oficial.
} 
ecuménico. También, unida a esta, una visión positiva de la modernización y el desarrollo social y económico. Sin embargo, poco a poco van surgiendo posiciones que, si bien se mantienen ajustadamente liberales en política, empiezan a esbozar apreciaciones críticas de la sociedad burguesa, tanto que hacia la década de los años 50 son cada vez más frecuentes dentro del mundo protestante los posicionamientos favorables al socialismo democrático (Míguez Bonino, 1995). Es de destacar que, en los ambientes universitarios, los protestantes apostarán al Movimiento Estudiantil Reformista, movimiento que reivindicaba la Reforma Universitaria de 1918 y del cual participaban comunistas, socialistas y radicales:

La crítica al modelo capitalista había estado presente en los movimientos ecuménicos como el Movimiento Estudiantil Cristiano (MEC) y la Unión Latinoamericana de Juventudes Evangélicas (ULAJE). En 1941, esta organización al convocar a su primer congreso continental tomó la consigna: "Con Cristo, un mundo nuevo" para paso seguido instar a confrontar contra "el presente sistema capitalista basado en la opresión y la desigualdad económica" y propiciar como alternativa "un sistema de cooperación". (Amestoy, 2011, p. 19)

En los años 60, el protestantismo se embarcó, casi de manera natural, en el proyecto desarrollista. Su naufragio empujó al movimiento ecuménico, que ya contaba para esta época con una importante participación latinoamericana, hacia posiciones cada vez más definidas de izquierda cristiana y de compromiso con los procesos revolucionarios y de descolonización del Tercer Mundo ${ }^{5}$. En América Latina las iglesias protestantes celebraron en 1961 la segunda Conferencia Evangélica Latinoamericana-CELA II- en Lima, Perú. Como resultado de esta reunión se constituiría la Junta Latinoamericana de Iglesia y Sociedad-ISAL-, con sede en Montevideo (Amestoy, 2011). Esta institución fue central en la promoción del debate teórico en torno a la relación entre iglesia y sociedad, adoptando poco a poco posiciones antiimperialistas y revolucionarias (Amestoy, 2011; Cervantes Ortiz, 2011).

Aparece aquí en nuestra historia una figura clave: Mauricio Amílcar López. Este intelectual ecuménico había nacido en Bahía Blanca en 1919, pero se crio y educó en Mendoza. Su familia formaba parte de la Comunidad Evangélica de los Hermanos ${ }^{6}$. Estudió filosofía en la Facultad de Filosofía y Letras de la

\footnotetext{
${ }^{5}$ W.E.B. Du Bois, importante teórico de los movimientos de la descolonización, ya había señalado desde temprano, concretamente en 1945, el importante papel que un movimiento misionero progresista podía llegar a jugar en los procesos políticos de la liberación africana.

${ }^{6}$ Los Hermanos de Plymouth (en inglés, Brethren of Plymouth), Hermanos libres o Asambleas de hermanos son algunos de los nombres con que se conoce el movimiento congregacionista protestante surgido en Irlanda hacia 1826 como respuesta, a su juicio, a la creciente ritualización del anglicanismo. En 1831, pasó a Inglaterra, principalmente a Plymouth y Bristol. Se caracteriza por la fraternidad entre sus miembros, el estudio literal de la Biblia, la insistencia en la absoluta
} 
Universidad Nacional de Cuyo, graduándose en 1946, y formó parte del Comité Organizador del Primer Congreso Nacional de Filosofía de 1949 (Weinstock, 1988).

En 1955 Mauricio López fue designado secretario para América Latina de la Federación Universal de Movimientos Estudiantiles Cristianos -FUMECy, en 1963, Secretario Adjunto del Departamento de Iglesias y Sociedad del Consejo Mundial de Iglesias en Ginebra. Desde este cargo, López ejerció una profunda influencia en los programas y orientación del CMI, haciendo extensivo el pensamiento de ISAL, del cual formaba parte junto a los uruguayos Emilio Castro y Julio de Santa Ana, y el estadounidense Richard Shaull (ALC, 2006; Amestoy, 2011; Paredes, 2010).

La Conferencia Mundial de Iglesia y Sociedad titulada "El compromiso cristiano en la revolución técnica y social de nuestro tiempo", celebrada en Ginebra en 1966, marcó "un punto de viraje en el movimiento ecuménico que colocó en el centro de las actividades del CMI el compromiso por la justicia social a escala mundial" (Quintero, 2006, p. 18). Esta conferencia fue organizada por Paul Abrecht ${ }^{7}$ y por el mismo López. En su declaración, la conferencia establecía que:

Como cristianos, estamos comprometidos a trabajar en favor de la transformación de la sociedad. En el pasado, lo hemos hecho usualmente mediante esfuerzos callados de renovación social, trabajando en y a través de las instituciones establecidas. Hoy, un número significativo de aquellos que se dedican al servicio de Cristo y de sus prójimos, asumen una posición más radical o revolucionaria. (Quintero, 2006, p. 18)

El CMI se transformaría desde entonces en la principal organización mundial de la izquierda cristiana, volviendo el término ecumenismo en casi un sinónimo de esta. Si bien nunca tomó una posición revolucionaria explícita y sí se expresaría a favor de la no-violencia ${ }^{8}$, tampoco condenó a quienes decidieron

necesidad de nacer de nuevo, la vuelta a los principios del cristianismo primitivo, el sacerdocio de todos los creyentes o la autonomía de las pequeñas asambleas locales, regidas por un consejo de ancianos. Las profundas divergencias entre John Nelson Darby y Benjamin Wills Newton provocarán la escisión del movimiento en darbystas - Exclusive Brethren- y plymutistas -Open Brethren- en 1848.

${ }^{7}$ El Rev. Paul Abrecht fue un especialista en ética que, bajo los auspicios del Consejo Mundial de Iglesias, tuvo un papel destacado en la formulación de la corriente principal del cristianismo que articuló una respuesta a los desafíos éticos modernos. Nació el 9 de diciembre de 1917, en Cincinnati. Obtuvo una licenciatura en Berkeley Baptist Divinity School y completó su tesis doctoral en el Seminario Teológico Unido de Nueva York. En 1949, Abrecht se unió al personal de Ginebra del Consejo Mundial de Iglesias, de nueva creación, y en 1954 se convirtió en director de su departamento de la Iglesia y Sociedad (The New York Times, 2005).

${ }^{8}$ En la consulta sobre 'Violencia y no violencia y la lucha por la justicia social', realizada en Cardiff, Gales, en 1972 (Quintero, 2006). 
involucrarse en los procesos revolucionarios de sus diferentes países. Según Guillermo Kerber:

La historia del CMI desde 1970 ha estado, por un lado, fuertemente influenciada por la TL [Teología de la Liberación] y específicamente la TLL [Teología de la Liberación Latinoamericana]. Por otro lado, como institución y a través de integrantes de su personal en Ginebra y en otros lugares ha contribuido y apoyado significativamente su desarrollo. (Kerber, 2013, p. 1823)

Estos posicionamientos le valieron a la institución muy fuertes críticas (Cviic, 1979) lo que se reflejaría en la ya marcada división del protestantismo mundial entre ecuménicos y evangélicos o fundamentalistas.

En la Argentina, los protestantes también se irían dividiendo entre un "polo histórico liberacionista", en el cual se agrupan las iglesias más antiguas y tradicionales - tales como luteranos, metodistas, valdenses, etc. - que participan en general del CMI y de sus iniciativas, y otro polo "conservador bíblico", compuesto mayoritariamente por bautistas y algunas denominaciones pentecostales, que practica una lectura literal de la Biblia y es, en general, conservador en asuntos políticos y sociales (Wynarczyk, 2009).

\section{Del DESARROLLISMO CATÓLICO Al MOVIMIENTO DE SACERDOTES DEL TERCER MUNDO}

En la década de los años 60 se asistió a profundos cambios dentro de la Iglesia Católica, no solo en América Latina, sino a nivel global. Luego de la Segunda Guerra Mundial, las sociedades modernas y las formas democráticas de gobierno parecían haberse consolidado para siempre. Los únicos cambios que, en ese entonces, se creían posibles no apuntaban hacia el restablecimiento de los antiguos regímenes aristocrático-monárquicos, sino al de sociedades socialistas. En un movimiento de reacomodamiento y de reconciliación con el siglo, el Papa Juan XXIII convocó, en enero de 1959, al Concilio Vaticano II, que se desarrolló entre 1962 y 1965. En él, los sectores liberales hegemonizarían la mayor parte de las reformas. Sin embargo, se presentaría también la oportunidad para que se hicieran oír las voces y los reclamos de los representantes del Tercer Mundo.

Luego del Concilio, Pablo VI lanzó la Carta Encíclica Populorum Progressio, sumándose a la oleada desarrollista iniciada tanto por las Naciones Unidas con la creación de la CEPAL, como por los Estados Unidos con la Alianza Para el Progreso. La encíclica católica, sin embargo, fue crítica del economicismo de estas iniciativas, proponiendo la noción de desarrollo integral; esto es, 
un desarrollo que interesara a los aspectos espirituales y éticos de la persona humana y no solo al crecimiento de su capacidad de producción y consumo.

Populorum Progressio recibió una calurosa acogida de parte de los sectores de la izquierda cristiana tercermundista y europea, que apuntaron a la ampliación y radicalización de su pensamiento en documentos como el Manifiesto de los Obispos del Tercer Mundo. En este escrito se presentaba una lectura de la encíclica que ya se encontraba muy lejos del desarrollismo católico y parecía más bien una confesión de fe revolucionaria:

Teniendo en cuenta ciertas necesidades para ciertos progresos materiales, la Iglesia desde hace un siglo, ha tolerado al capitalismo con el préstamo a interés legal y sus otros usos poco conformes con la moral de los profetas y del Evangelio. Pero ella no puede más que regocijarse al ver aparecer en la humanidad otro sistema social menos alejado de esta moral. [...] Lejos de contrariarse con él, sepamos adherirlo con alegría, como a una forma de vida social mejor adaptada a nuestro tiempo y más conforme con el espíritu del Evangelio. (Obispos del tercer mundo, 1968)

Este Manifiesto fue firmado por dieciocho obispos de países tercermundistas y socialistas (Yugoeslavia y China). Si bien entre ellos no se contaba ninguno argentino, el impacto del documento sería determinante en la historia de la izquierda cristiana en este país.

Pocos meses después de que se publicara -agosto de 1967-el Manifiesto de los Obispos del Tercer Mundo comenzó a circular de mano en mano entre el clero argentino ganando, al decir de José Pablo Martín, "muchas mentes y corazones" (Martín, 2010, p. 101). Un pequeño grupo de sacerdotes ${ }^{9}$ que recibió el documento, concibió la idea de adherirse al mismo y de buscar otras adhesiones por parte de curas de las distintas diócesis argentinas. Para diciembre de 1967, el Manifiesto contaba con 270 adhesiones y había llegado a cerca de 400 en los primeros meses de 1968. Este acto declaratorio constituyó, casi sin que lo hubiesen sabido sus participantes, la fundación del Movimiento de Sacerdotes del Tercer Mundo (MSTM).

Ante la entusiasta respuesta que el documento generó entre el clero argentino, se decidió convocar para mayo de 1968 en Colonia Caroya, Provincia de Córdoba, un primer Encuentro Nacional, en el cual participaron 21 representantes de 13 diócesis. El movimiento era horizontal y tenía, durante estos primeros tiempos, una estructura mínima. Tanto es así que su nombre provino de la apropiación y readaptación del mote de "curas tercermundistas" que la prensa de la época les otorgó. En Mendoza, en el periodo entre 1968 y 1969, la importante

\footnotetext{
${ }^{9}$ Se trata de Héctor Botán, Miguel Ramondetti y Rodolfo Ricciardelli. A su vez estos tres sacerdotes habían recibido el documento - una traducción del francés- de manos del obispo de Goya, Alberto Devoto.
} 
sección local del Movimiento se fue involucrando en distintas luchas y conflictos sindicales locales; entre ellos, el apoyo al movimiento de contratistas en el departamento de Lavalle, la huelga de obreros gráficos y de los petroleros privados. Participaron también de la creación de la sección Mendoza de la CGT de los Argentinos (Concatti, 2009).

\section{LA ACCIÓN POPULAR ECUMÉNICA (APE) Y EL MOVIMIENTO ECUMÉNICO EN ARGENTINA Y MENDOZA}

\section{Católicos y protestantes...}

La historia del MSTM en Mendoza estuvo entrelazada a la del Movimiento Ecuménico. Puede decirse que cada uno, desde un principio, fue determinante en el desarrollo del otro. En el momento de adherirse al Manifiesto de los Obispos, Rolando Concatti, Oscar Bracelis y Agustín Totera se encontraban en Francia, exiliados luego del "conflicto de los 27 " 10 . Desde allí comunicaron entusiasmados la noticia a los remanentes del grupo de curas rebeldes, todavía en Mendoza. También en París, Bracelis y Concatti se reencontraron con un viejo conocido: Mauricio López, quien acababa de finalizar su tarea en el CMI de Ginebra y, antes de volver a la Argentina, cursaba estudios en La Sorbona.

Quince años antes en Mendoza, Rolando Concatti, militante juvenil de la recientemente fundada Democracia Cristiana, se había enfrentado ideológicamente a López. El docente protestante y el estudiante católico eran parte de dos corrientes enfrentadas en el seno de la universidad argentina. López participaba del reformismo universitario; Concatti de la corriente católica del humanismo, al igual que Enrique Dussel, quien llegó a presidir el centro de estudiantes de la Facultad de Filosofía y Letras (Dussel, 1998) ${ }^{11}$. El exsacerdote recordaba la escaramuza en un artículo publicado originalmente en el diario mendocino Los Andes en 2002 y luego republicado en su libro de 2011 titulado Ensayos entre luces y sombras:

Era yo para aquel entonces apenas un adolescente y me inauguraba en el catolicismo, que me llegaba en sus formas bien paternalistas, nulo de Biblia o de filosofía, más cerca de la

\footnotetext{
${ }^{10}$ Se trató de un conflicto que, entre 1963 y 1966, enfrentó a un grupo de 27 sacerdotes de la Provincia de Mendoza con el obispo auxiliar José Miguel Medina. Si bien se trató al principio de un malestar del joven clero mendocino con la autoritaria figura de Medina, pronto derivó en un enfrentamiento entre conciliares y pre-conciliares en el seno de la Iglesia argentina. Ver al respecto el capítulo del libro de Rolando Concatti, Testimonio cristiano y resistencia en las dictaduras argentinas. El movimiento ecuménico en Mendoza 1963 - 1983 (2009, pp. 75-85).

${ }^{11}$ Sobre reformismo y humanismo universitario puede consultarse Pis Diez, 2012.
} 
espada de Constantino que de las parábolas del profeta de Nazareth. Militantes, turbados por los rumores del brillo del joven profesor protestante, con otros de entonces, con Enrique Dussel o Eugenio Carbonari, fuimos a escucharlo y en alguna medida a desafiarlo, a cruzar nuestros estoques de devoción y rosario contra su palabra ya madura. Pasó lo irremediable: nos dejó en silencio, pero sin humillarnos; nos ilustró sobre la Biblia, su mensaje abierto, sobre el porvenir de la fe y el diálogo de los creyentes. Siempre sonriente, dialogal, sin posturas de maestro. Después de algunos intentos ya no volvimos, cerriles en nuestro empeño. Pero lo que él representaba ya nos había herido, y en el andar de nuestros propios azares, con los años, otras dentelladas de la misma estirpe, dulces y terribles, no harían sino terminar de cambiarnos, o al menos, de erosionar poco a poco el confortable edificio de los dogmas baratos. (Concatti, 2011, p. 188)

Este reencuentro de los comprovincianos no sólo sería humano, sino que ahora los curas, transformados por el conflicto con la jerarquía eclesiástica y el tiempo transcurrido en Europa, caerían en la cuenta de que sus coincidencias ideológicas los acercaban decididamente al viejo maestro protestante. Antes todavía de volver a la Argentina, "entre los estruendos y las corridas de 'Mayo del 68 '", acordaron unir sus fuerzas y construir, en Mendoza, el nuevo movimiento ecuménico. A su vez, López demostró desde el inicio un profundo interés en el Movimiento que sus compañeros católicos estaban creando, el cual se reflejaría en los dos volúmenes de su libro póstumo Los cristianos y el cambio social en la Argentina (López, 1989; 1992).

\section{Los cursos de formación teológica y el aluvión de los años 70}

Ya en Mendoza, el Movimiento Ecuménico daría sus primeros pasos realizando actividades que podrían ser caracterizadas como de un ecumenismo doctrinal. A principios de 1969, se iniciaron los Cursos de formación teológica, desarrollados durante tres años en la Iglesia Metodista de Mendoza. Los responsables fueron el tercermundista Héctor Gimeno, antiguo miembro de "Los 27", y un jovencísimo Aníbal Sicardi, pastor metodista y periodista. La asistencia a estos cursos fue masiva, teniendo en cuenta que se realizaba en una ciudad del interior de mediana población como Mendoza y que el cursado era regular y bastante intensivo; esto es, dos veces por semana. Se inscribieron en un principio cerca de 300 personas, de las cuales 200 mantuvieron su participación hasta el final. Entre los docentes cabe destacar la intervención del pastor metodista Néstor Míguez, el filósofo Enrique Dussel, que iniciaba su etapa americana luego de diez años de estudios en Europa, Rolando Concatti y Oscar Bracelis, quien había sido rector del seminario de Lunlunta en Mendoza y asesor de la JOC -Juventud Obrera Católica-en los años 50 y primeros 60, Alieda Verhoeven, metodista, primera mujer pastora de la Argentina, el helenista Vicente Cicchitti Marcone y otras figuras de la intelectualidad mendocina de la época (Concatti, 2009). 
Sin embargo, este movimiento -que en un principio se presentaba como una iniciativa intelectual y doctrinal- tardaría muy poco en transformarse, siguiendo el espíritu de la época, en un frente común de intervención política y social. En 1970, las intensas lluvias del verano mendocino provocaron el colapso de una de las defensas aluviales que protegían la ciudad: el dique Frías. Un torrente de barro y escombros bajó desde el piedemonte arrasando todo a su paso. Como siempre, la mayoría de los damnificados del aluvión se contaron entre los sectores más humildes de la población. La mitad de las víctimas fatales, de un total de 24, se localizaron en la zona de la Villa del Parque, en el suroeste del conglomerado urbano de Godoy Cruz, donde la gente había construido sus precarias viviendas en los márgenes y el lecho del zanjón seco. (Baraldo, 2005)

Los militantes católicos y protestantes encontraron entonces una muy fuerte interpelación para dejar de lado por un momento las discusiones doctrinales y salir juntos a la calle. El grupo organizador de los Cursos de formación teológica se transformó entonces, desde el local de la Iglesia Metodista, en coordinador de la ayuda a la población afectada. Luego, el movimiento que recién se formaba, se abocó a las tareas de reconstrucción y de ayuda a los damnificados, pero no desde una perspectiva asistencialista, sino a través de la organización política de los propios pobladores que disputarían con el gobierno provincial y nacional los terrenos y los recursos para reconstruir sus viviendas, esta vez en condiciones dignas, en lo que hoy es el Barrio Virgen del Valle, en el departamento de Godoy Cruz. La unidad en la acción entre católicos y protestantes terminaría por derribar lo que todavía quedaba de recelo y desconfianza (Baraldo, 2005; Concatti, 2009).

\section{La casa de la calle Catamarca y el ILPH}

En paralelo a estos hechos, los tercermundistas Bracelis y Concatti alquilaron una casa en pleno centro mendocino. Allí se fueron a vivir junto a otros dos sacerdotes: Carlos Pujol y el español Antonio Echave. La casa no sólo funcionaba como vivienda de los sacerdotes, sino que era un centro político y cultural para todas las expresiones de la nueva militancia (Álvarez, 2010).

A la denominada Casa de la Calle Catamarca comenzaron a llegar jóvenes universitarios y sindicalistas, que se autodenominaban peronistas pero que eran, sin embargo, marginados y ninguneados por las estructuras locales del Partido Justicialista. Los sacerdotes, que habían asesorado a muchos de ellos anteriormente en las épocas de la J.U.C. -Juventud Universitaria Católica- y que incluso habían sido profesores de algunos que también habían pasado por el 
seminario de Lunlunta, intentaron contenerlos y encauzarlos formando la Coordinadora Peronista que, como su nombre lo indica, aspiró a coordinar todos los grupos sueltos que trabajaban en la provincia. Las banderas de la Coordinadora eran la horizontalidad política, la profunda inserción en el trabajo de masas y el trabajo en relación directa con las bases (Álvarez, 2010). Cumplió también un papel importante al establecer los lazos con las corrientes nacionales del peronismo revolucionario. Así, se establecería primero la relación con la CGT de los Argentinos y, posteriormente, el encuadramiento dentro del espacio nacional del Peronismo de Base ${ }^{12}$ (Álvarez, 2010).

También en la Casa de la Calle Catamarca empezaron a funcionar los Cursos Ecuménicos de Teología. Allí Concatti escribió el libro Nuestra Opción por el Peronismo y el grupo de sacerdotes de Mendoza el documento Qué pensamos, llevado al Tercer Encuentro Nacional del MSTM y que había sido discutido en su etapa de elaboración con Mauricio López y Alieda Verhoeven. También circularon por esta casa figuras intelectuales locales y nacionales: Arturo Roig, Enrique Dussel, Raimundo Ongaro, Ricardo Carpani, José Pablo Feinmann, Alcira Argumedo, Norman Briski y un largo etcétera. Las relaciones que el grupo de Mendoza tejió durante esta época se reflejarían luego, en los años 80, en las diversas colaboraciones externas para la revista Alternativa Latinoamericana (Concatti, 2009).

Hacia fines de 1971 empezó a tomar cuerpo la idea de formar una institución que se dedicara a la promoción y formación de dirigentes sociales. Alberto Isuani, - exmilitante estudiantil en la Facultad de Ciencias Políticas y Sociales de la UNCuyo y participante de la Acción Católica, recordaba, en una entrevista realizada por Natalia Baraldo que luego es retomada en Testimonio cristiano, el libro de Rolando Concatti, una reunión en la cual participó junto a Oscar Bracelis, Ezequiel Ander-Egg, José Míguez Bonino y Alieda Verhoeven:

En esa reunión se habló de la posibilidad de conseguir fondos del Consejo Mundial de Iglesias con el cual Alida y Míguez Bonino tenían aceitadas relaciones, con el fin de crear un Instituto que se dedicara a la formación política y a promover la militancia social, ya

${ }^{12}$ El Peronismo de Base fue una de las corrientes del peronismo revolucionario. Se origina a partir de las FAP (Fuerzas Armadas Peronistas) y de los remanentes de la CGTA de Raimundo Ongaro. A diferencia de otras corrientes, como Montoneros, sus militantes eran mayormente viejos peronistas de la época de la Resistencia Peronista. Políticamente se caracterizaron por proponer una alternativa independiente de la clase obrera a las dirigencias burocráticas, planteando un movimiento de base que se distanciaba incluso de la figura misma de Perón. Si bien no renegaban de la lucha armada, la concebían como una herramienta más entre otras, subordinada a la política. Fueron muy críticos del vanguardismo y la militarización de otras organizaciones del peronismo revolucionario y de la izquierda. Ver Raimundo, 2004; Stavale, 2010. Un compendio documental importante para trazar la historia de esta corriente es Duhalde y Pérez, 2002. 
que estos pastores sostenían que entre las autoridades del Consejo Mundial de Iglesias se estaba produciendo un cambio trascendental en su manera de relacionarse con el tercer mundo. Estaban cansados de destinar ayuda de forma directa al Tercer Mundo apuntando a la creación de infraestructura religiosa o social (Iglesias, centros de salud, viviendas o ayuda social directa) y lo que se empezaba a proponer era destinar la ayuda a la formación y capacitación de dirigentes políticos, sindicales y sociales y a las tareas de organización social que fueran capaces de motorizar un proceso de cambio que permitiera crear sistemas políticos que pudieran superar las lacras del subdesarrollo y no solamente mitigarlas. (Concatti, 2009, p. 121)

Así surgió, en 1972, el Instituto para la Liberación y Promoción Humana -ILPH-, que funcionó inicialmente en las dependencias del IASyF o Instituto de Acción Social y Familiar. El ILPH se dividía en tres áreas: Educación y Organización Popular, a cargo de Bracelis; Estudios y Formación Política, bajo la tutela de Isuani y Ander-Egg; y Coordinación Administrativa y de Relaciones Nacionales e Internacionales, dirigido por Alieda Verhoeven (Concatti, 2009).

\section{APE y la FEC: el movimiento popular ecuménico}

Como una manera de institucionalizar este movimiento popular ecuménico, que venía funcionado con acciones de base en Mendoza, pero también en distintos rincones de la Argentina desde, por lo menos, 1967, se decidió fundar una organización nacional, la Acción Popular Ecuménica.

A.P.E. se definía a sí misma como:

[...] una organización que desde una perspectiva popular y con un sentido amplio de ecumenicidad, se constituye como punto de confluencia de sectores de las iglesias y de la militancia política, que ya participan junto a la clase trabajadora en la lucha por la liberación de todo el pueblo y cuyo objetivo estratégico es la construcción del socialismo nacional y latinoamericano. Sin embargo. A.P.E, no es ni un organismo partidario, ni una institución de las Iglesias, y las relaciones con unos y con otros, se plantean desde la plataforma antes mencionada.

Para el logro de sus objetivos, A.P.E. agrupa a cristianos y no cristianos, que impulsan, fomentan y participan en ella, para ayudar a crear condiciones de vida más humanas. Los cristianos asumen además, la responsabilidad particular de impulsar la participación de las iglesias en el proceso de liberación, puesto que es inherente a la misión de las mismas y un imperativo que debe ser asumido inexorablemente.

(...)

En suma: A.P.E, es un punto de encuentro, apoyo y vinculación de grupos que participan en el proceso de liberación. No es un frente político en sentido estricto, sino una organización donde se pone de manifiesto la alianza estratégica para la construcción del socialismo nacional. (A.P.E., 1973, p. 162)

El movimiento popular ecuménico, del cual A.P.E. pretendía ser la representación institucional, se pensaba como un movimiento de ecumenismo ampliado, que no sólo incluyera a los cristianos protestantes y ortodoxos, como en los orígenes del movimiento, sino a todos los cristianos -católicos también-, a representantes de otras creencias religiosas no cristianas, así como también a 
aquellos no religiosos o no creyentes que se encontraran comprometidos en los procesos de liberación.

En Mendoza, a su vez, se pensaba también en la creación de una institución que aglutinara y diera una mayor organización a las múltiples experiencias del movimiento ecuménico, tales como el ILPH, los Cursos de Teología, las experiencias de Educación Popular en clave freireana en los barrios del Gran Mendoza, la acción de promoción, acompañamiento y articulación con los sindicatos, etc. De esa manera, los grupos ecuménicos mendocinos decidieron en 1972 crear la Fundación Ecuménica de Cuyo, pensada como la representación regional de A.P.E.

A.P.E. y F.E.C. no eran entonces organizaciones no gubernamentales, en el sentido que vino a tomar este término en los años 80 y 90, sino organizaciones políticas no partidarias en las que confluían, a pesar de ser mayoritario el Peronismo de Base, representantes de diferentes tendencias del peronismo de izquierda y de otras opciones progresistas no peronistas. Por otro lado, al abrirse a los no creyentes, su especificidad religiosa parecía también desdibujarse.

Sin embargo, una perspectiva de izquierda cristiana era determinante, perspectiva en la cual podían incluirse sin problemas tanto los peronistas Bracelis, Concatti y Verhoeven como el radical Isuani. Esa perspectiva centrada en la ética cristiana como principio rector de la conceptualización política debía ser compartida también, al menos de forma implícita y de una manera secularizada, por los no creyentes. Era esa misma perspectiva la que volvía central la confluencia en el trabajo de base, la convivencia cara a cara de la militancia política entre sí y con el pueblo. Las banderas ideológicas eran consideradas secundarias frente al activismo y el basismo, siendo quizá la del cristianismo la única permitida, y eso hasta un cierto límite. Se sentaban entonces desde la izquierda cristiana las bases de una izquierda social laica.

\section{CONCLUSIÓN: IZQUIERDA CRISTIANA, MOVIMIENTO ECUMÉNICO, TEOLOGÍA DE LA LIBERACIÓN}

En el presente artículo hemos repasado brevemente una historia del movimiento ecuménico, del movimiento cristiano-liberacionista y de la izquierda cristiana, con especial atención a algunas experiencias de estos movimientos en la Mendoza de los años 60. El resultado de dicho análisis histórico es establecer el sentido de tales rótulos, que en muchas ocasiones refieren a los mismos movimientos y que, por lo tanto, suelen ser utilizados de manera intercambiable. 
Hemos visto cómo, a veces, se trata de definiciones concéntricas. Otras, nos sirven para destacar matices particulares o para designar distintos aspectos de los mismos movimientos históricos.

Comencemos entonces por la definición de izquierda cristiana. Entendemos por tal a aquella forma de anti-capitalismo cristiano, ya sea católico o protestante, que, a diferencia de la izquierda tradicional o marxista, no basa su crítica de la sociedad capitalista moderna en aquellas potencialidades de emancipación humana que el mismo desarrollo capitalista ha engendrado, potencialidades que según el marxismo solo podrían desenvolverse plenamente en el marco de una reorganización socialista de la sociedad. A diferencia del marxismo, la $i z$ quierda cristiana construye su crítica fundándose en la ética cristiana del amor universal; esto es, en el supuesto de que, en tanto hijos e hijas de Dios, todos los hombres y mujeres del mundo son hermanos y hermanas. Lejos de ser entendida como el resultado superestructural-ideológico de un modo o modos de producción particulares, dicha ética del amor universal funge como locus desde el que puede calificarse la justicia o injusticia del capitalismo o de cualquier otro sistema social o forma civilizatoria ${ }^{13}$.

Por movimiento ecuménico referimos a dos movimientos particulares $\mathrm{o}$, mejor dicho, a dos momentos históricos de un mismo movimiento, los cuales no se excluyen, sino que a veces coexisten o se solapan. Por un lado, al movimiento que tendió y tiende a la reunión de las iglesias cristianas "como expresión de la universalidad del cristianismo y como signo visible para mantener la fe" (Brachetta, s.f.). El nacimiento de dicho movimiento se encontró motivado por los dilemas éticos planteados a los cristianos por las dos guerras mundiales y por los desafíos de la misión evangelizadora en el mundo colonial no-cristiano (Brachetta, s.f.; Míguez Bonino, 1995). Se centró en la fe compartida; esto es, en la común creencia de las distintas iglesias en Jesucristo como hijo de Dios y salvador de la Humanidad. Si bien se trata de un movimiento progresista y que logra trascender el fundamentalismo de las iglesias cristianas -llevándolas a reconocer unas en las otras un camino legítimo de acercamiento a Dios, más allá de las diferencias teológicas-, no podemos englobar a este primer momento o acepción del movimiento

\footnotetext{
${ }^{13}$ Además, a diferencia de otras manifestaciones de anti-capitalismo cristiano que buscan la restauración de los modos de dominación jerárquicos y patriarcales típicos de las sociedades precapitalistas, la izquierda cristiana es profundamente democrática e igualitarista. Esto para distinguirla de formas cristianas, corporativistas o restauracionistas, como el nacionalismo católico, que se declaraba por igual anticomunista y anticapitalista. Sin embargo, su acción se enmarcaba abiertamente en la defensa de las jerarquías patriarcales y coloniales todavía vigentes en nuestras sociedades.
} 
ecuménico dentro del término izquierda cristiana, a pesar de que alguna de sus corrientes internas pudiera identificarse con ella ya para esta época ${ }^{14}$.

Ahora bien, existe una segunda acepción de ecumenismo que es más amplia y restringida a la vez, y que se corresponde con una segunda etapa o momento del movimiento, en la cual la noción de izquierda cristiana es indispensable para definirlo y dentro del cual dicha noción es, al mismo tiempo, trascendida. Se trata de un movimiento, heredero del primer ecumenismo, que amplía la unión de las iglesias cristianas primero a las religiones abrahámicas -judaísmo, islam-, y luego a aquellas creencias y doctrinas - y a los individuos que las profesan-que comparten un compromiso generoso para "la superación de situaciones de desigualdad o injusticia social y discriminación social, racial, religiosa, sexual y en la defensa de los derechos humanos" (Brachetta, s.f.). Este segundo momento no se centra ya en la fe cristiana compartida, sino en valores éticos compartidos para juzgar la justicia o injusticia de una realidad social dada. Al tratarse de un movimiento de izquierda fundamentado en una ética, lleva implícita la idea de izquierda cristiana. Sin embargo, trasciende al cristianismo como identidad porque incorpora el diálogo con otras éticas religiosas y no-religiosas y toma los valores compartidos como punto de partida.

Otra definición importante es la de Teología de la Liberación. Entendemos, junto a autores como Löwy (1999) o Silva Gotay (1981), que se trata de la cristalización teórica de la praxis de un amplio movimiento social, el cristianismo liberacionista, el cual también puede, a su vez, ser englobado dentro del término más general de izquierda cristiana. La teología de la liberación, sin embargo, se distingue de otras corrientes de izquierda cristiana en que es un fenómeno exclusivamente latinoamericano y que da cuenta de las particularidades de los procesos de este continente signados por las luchas contra la dependencia y el neocolonialismo. En cuanto a este punto, coincidimos con Löwy frente a, por ejemplo, Boer (2011), quien niega la exclusividad latinoamericana de la teología de la liberación, señalando que debe hablarse en cambio de muchas "teologías de la liberación", antes y después de ésta y en diversos contextos mundiales. Para nosotros, sin embargo, más allá del uso genérico que se puede hacer del término liberación, en América Latina tiene un significado muy concreto, vinculado a la tradición anti-imperialista y revolucionaria y a las teorías dependentistas de los años 60. Parafraseando al poeta salvadoreño Roque Dalton, no es lo mismo la liberación de la enajenación que la liberación de la nación ajena.

\footnotetext{
${ }^{14} \mathrm{Y}$ que incluso estas corrientes se volvieran luego hegemónicas dentro del movimiento.
} 
A pesar de sus limitaciones, que ya han sido oportunamente señaladas por otros autores (Boer, 2011; Pimentel Chacón, 2008), la obra de Michael Löwy rescata acertadamente la potencialidad anticapitalista encerrada en la ética cristiana del amor universal. Sin embargo, más allá de toda simplificación, la historia que aquí hemos expuesto revela que fueron muchas veces los protestantes quienes tomaron nota más tempranamente y se movilizaron de acuerdo con ella.

\section{BIBLIOGRAFÍA}

A.P.E. (Acción Popular Ecuménica). (1973). Asamblea Nacional de A.P.E. / Trasfondo y definición de A.P.E. Cristianismo y Sociedad, XI(35-36), 158-164.

ALC. (2006). Raiser destaca aporte latinoamericano en conferencia sobre Iglesia y Sociedad (1966). Boletín Informativo Centro Basilea, (23), 18.

Álvarez, Y. (2010). La Revolución argentina y los inicios de la radicalización: juventud universitaria y catolicismo posconciliar en Mendoza (1966-1973). Latinoamérica. Revista de Estudios Latinoamericanos, (51), 85-108. https://doi.org/10.22201/cialc.24486914e.2010.51.25996

Amestoy, N. R. (2011). De la crisis del modelo liberal a la irrupción del movimiento Iglesia y Sociedad en América Latina (ISAL). Teología y cultura, VIII(13), 7-26.

Baraldo, N. (2005). Estrategias de organización barrial en la periferia de la ciudad. Mendoza 1969 - 1973. Actas de las X Jornadas Interescuelas/Departamentos de Historia (págs. 1-16). Escuela de Historia de la Facultad de Humanidades y Artes, Universidad Nacional del Rosario; Departamento de Historia de la Facultad de Ciencias de la Educación, Universidad Nacional del Litoral.

Boer, R. (2011). The Alchemy of Michael Löwy. En R. Boer (ed.), Criticism of Theology. On Marxism and Theology III (pp. 159-200). Brill. https://doi.org/10.1163/ej.9789004189744.i-358.21

Brachetta, M. T. (s.f.). Ecumenismo latinoamericano. En H. Biagini, \& A. Roig (eds.), Diccionario del Pensamiento Alternativo II. http://www.cecies.org/articulo.asp?id=146

Cervantes Ortiz, L. (2011). En los 50 años de ISAL: Entrevista a Julio de Santa Ana. Agencia Latinoamericana y Caribeña de Información.

Concatti, R. (2009). Testimonio cristiano y resistencia en las dictaduras argentinas. El movimiento ecuménico en Mendoza 1963-1983. Centro Nueva Tierra.

Concatti, R. (2011). Mauricio López, retrato de un hombre solidario. En R. Concatti (ed.), Ensayos entre luces y sombras (pp. 187-189). El Amante Universal.

Cviic, K. F. (1979). The politics of the World Council of Churches. The World Today, XXXV(9), 369-376.

Du Bois, W. (1945). Color and Democracy. Colonies and Peace. Harcourt, Brace and Company. https://doi.org/10.2307/2263087

Duhalde, E. L., \& Pérez, E. M. (2002). De Taco Ralo a la alternativa independiente. Historia Documental de las Fuerzas Armadas Peronistas y del Peronismo de Base. Tomo I: las FAP. De la Campana.

Dussel, E. (1998). En búsqueda del sentido (origen y desarrollo de una filosofía de la liberación). Anthropos, (180), 13-36. 
Hinkelammert, F. (1981). Las armas ideológicas de la muerte. (2ª edición). Departamento Ecuménico de Investigaciones.

Kerber, G. (2013). Teología de la Liberación y movimiento ecuménico: breve reflexión desde una práctica. Horizonte, XI(32), 1813-1826.

López, M. A. (1989). Los cristianos y el cambio social en la Argentina. Panorama histórico social 1965 - 1975 (vol. 1). Acción Popular Ecuménica; Fundación Ecuménica de Cuyo.

López, M. A. (1992). Los cristianos y el cambio social en la Argentina. Análisis de documentos (vol. 2). Acción Popular Ecuménica; Fundación Ecuménica de Cuyo.

Löwy, M. (1999). Guerra de Dioses. Religión y política en América latina. Siglo XXI.

Löwy, M., \& Sayre, R. (2008). Rebelión y melancolía: el Romanticismo como contracorriente de la modernidad. Nueva Visión.

Mallimaci, F. (2008). Nacionalismo y cultura laica en Argentina. En R. J. Blancarte (ed.), Los retos de la laicidad y la secularización en el mundo contemporáneo (pp. 239-262). El Colegio de México, Centro de Estudios Sociológicos.

Martín, J. P. (2010). El Movimiento de Sacerdotes para el Tercer Mundo. Un debate argentino. Universidad Nacional de General Sarmiento.

Míguez Bonino, J. (1995). Rostros del protestantismo latinoamericano. Nueva Creación.

Obispos del tercer mundo. (1968). El Manifiesto de los obispos del tercer mundo: una respuesta al clamor de los pobres. Búsqueda.

Paredes, A. (2010). Los escritos de Mauricio López en el extranjero (1955 y 1969). Fundamentos en Humanidades, XI(1), 101-120.

Pimentel Chacón, J. (2008). El Espejo Roto (I): Michael Löwy y los cristianismos liberacionistas latinoamericanos. Siwó'. Revista de Teología, (1), 217-266.

Pis Diez, N. (2012). La política universitaria peronista y el movimiento estudiantil reformista: actores, conflictos y visiones opuestas (1943-1955). Los trabajos y los días, (3), 41-63.

Quintero, M. (2006). ¿Reforma o revolución? Cuarenta años después, el debate continúa. Boletín Informativo Centro Basilea, (23), 18.

Raimundo, M. (2004). Izquierda peronista, clase obrera y violencia armada: una experiencia alternativa. Cuadernos del CISH, (15-16), 99-128.

Silva Gotay, S. (1981). El pensamiento cristiano revolucionario en América Latina y el Caribe. Implicaciones de la teología de la liberación para la sociología de la religión. Sígueme.

Stavale, M. (2010). Del peronismo al alternativismo. Un recorrido a través de la evolución ideológica de las Fuerzas Armadas Peronistas. VI Jornadas de Sociología de la UNLP (pp. 1-20). Universidad Nacional de La Plata, Facultad de Humanidades y Ciencias de la Educación, Departamento de Sociología.

The New York Times. (2005, 19 de junio). Paul Abrecht, 87, Church Ethicist, Dies. The New York Times. https://www.nytimes.com/2005/06/19/us/paul-abrecht-87-church-ethicist-dies.html

Visser 't Hooft, W. A. (1982). The Genesis and Formation of the World Council of Churches. World Council of Churches.

Weber, M. (1978). Sociología de la religión. La Pléyade.

Weinstock, R. (1988). Mauricio Amílcar López. Editorial Universitaria de San Luis.

Wynarczyk, H. (2009). Ciudadanos de dos mundos. El movimiento evangélico en la vida pública argentina 1980-2001. UNSAM Edita.

Zanatta, L. (1996). Del Estado liberal a la Nación Católica. Iglesia y Ejército en los orígenes del peronismo. 1930-1943. Universidad Nacional de Quilmes. 